\title{
The Research of the Transferring Knowledge between the Parent and Subsidiary Company (Based on Taiwan)
}

\author{
Junshan Wen, Rui Yang \\ South China University of Technology Guangdong, Guangzhou, China \\ Email: 820677124@qq.com
}

Received 28 February 2014; revised 24 March 2014; accepted 22 April 2014

Copyright (C) 2014 by authors and Scientific Research Publishing Inc.

This work is licensed under the Creative Commons Attribution International License (CC BY). http://creativecommons.org/licenses/by/4.0/

(c) (i) Open Access

\begin{abstract}
With knowledge economy age's coming, knowledge transfer is the significant method to make organization more competitive, and also help organizational innovation, which can help organization has its own core competence. Information processing is no longer the key bottleneck in the organization, the biggest challenge facing the organization, but the knowledge creation and transfer to promote a transnational knowledge transfer research in the ascendant. As in Taiwan, the economic downturn and the rising cost force Taiwan-funded enterprises to continue to find a way out, while the mainland has good infrastructure, abundant labor, and similar cultural background, so the mainland becomes the best choice of Taiwan businessmen. But even so, they still face the problem of the effectiveness of knowledge transfer. In this study, the relationship between the factors in the parent-subsidiary of Taiwan-funded starts to investigate the effectiveness of knowledge transfer from the communication channels, the level of trust, organizational distance and cultural distance four dimensions. Then we expand social communication channels to increase the knowledge, training, and the relevant recommendations to enhance the building of enterprise culture of high-tech enterprises.
\end{abstract}

\section{Keywords}

Knowledge Transfer; Parent-Subsidiary Company; Taiwan-Funded Enterprise

\section{Introduction}

Management guru Peter Drucker said, “The next social production tool is knowledge, knowledge workers will quickly become the largest labor groups, and have become the main force of wealth creation. Success of each company, or even survival, will increasingly rely on knowledge of the performance of the labor force.” While 
Zander \& Kogut [1] study showed that competitive pressures among enterprises continue to encourage enterprises to carry out technological innovation and knowledge transfer and imitation. After 1996, the status of knowledge in the economy and the enterprise paid further attention. In this year, the Organization for Economic Cooperation and Development (OECD) for the first time has the concept of "knowledge economy" in the documents of international organizations, in a report entitled "knowledge-based economy", the theme of the report. The OECD gives the definition of this concept: the knowledge economy is built on knowledge and information on the production, distribution and use of the economy, knowledge-based resources, and an economic form.

Type of knowledge exists in many forms and what kind of knowledge is consistent becomes the ultimate source of competitive advantage in this standard. Studies have shown that static knowledge stock enterprise for business innovation and development impact are far less effective movement and flow of knowledge [2]. Because knowledge is a corporate resource, it differs from the land, manpower and other resources that do not have knowledge of the properties of diminishing marginal benefit, but the greater range of shared knowledge and capabilities are, the more value can be reflected and enhanced. Szulanski believes that the ability to transfer best practices within the enterprise is the key competitive advantage of the unique capabilities within the enterprise made by other companies in the absence of basic situation which is difficult to imitate. O'Dell and Gupta [3] also believe that if enterprises can successfully identify the transfer of best practices inside the organization. Meanwhile, a large number of empirical data also confirms this view and the return on assets inside the United States relies on 3 M's technology, relies on additional services and gets $50 \%$ higher than the return on assets. In 3014, the UK was the major innovation in 1945-1979; nearly 59\% of the innovation came from the transfer of knowledge within the organization and flow. Arthur Andersen's knowledge management made famous formula: $\mathrm{KM}=(\mathrm{P}+\mathrm{I})^{\mathrm{S}}$. KM is on behalf of knowledge management activities, "P" is on behalf of employees (people), "I" is on behalf of information , "+" is on behalf of Technique, "S" representatives knowledge sharing. This equation shows that the flow of knowledge sharing will bring the organization grow geometrically.

From research and business experience, both theorists and scholars reveal such a conclusion, the effectiveness of knowledge transfer within the enterprise level, the organization is indeed a source of competitive advantage. Knowledge transfer organizations can rapidly expand the stock of knowledge to enhance the competitiveness of enterprises, to avoid duplication of investment companies, to reduce development costs of technology and management knowledge, but also to maintain a competitive advantage for competitors to imitate [4].

Transfer of knowledge between the parent and subsidiary companies has gradually become the internal focuses of research in recent years among scholars. With the deepening of cross-strait exchanges in Taiwan and rising operating costs, more and more companies choose to invest in the mainland factories, researches and developments and the gradual shifts from the original design. Knowledge management and transfer, especially within the enterprise of knowledge transfer have become an important factor in the success of business in the mainland [5]. So between Taiwan and the mainland parent companies, the current evaluation of knowledge transferring [6], both the degrees of attention for a variety of different factors that affect the transfer are the same and what factors influence the success of the transfer of the biggest constitutes the core issues of this study.

The purpose of this paper is to absorb and learn about domestic and multinational knowledge transfer theory, through empirical research, from the perspective of the relationship between the parent company to build a theoretical model, to select the angle of the network structure to study the internal organizational level of knowledge transfer circumstances and effects in order to put forward some new ideas and perspectives for research in the field, which will be helpful for future research.

\section{Literature Review}

\subsection{The Concept of Knowledge Transfer}

Knowledge transfer as a knowledge economy era's fresh proposition occupies an increasingly important position in the study of knowledge management, and because knowledge itself is an invisible but different form of objective thing, the study of knowledge transfer will become a rich and complicated.

Teece in 1977 first proposed the idea of knowledge transfer, but initial studies tended to focus on knowledge transfer within the organization, and less on knowledge transfer between organizations discussed. Teece's 27 projects carried out empirical research, and he found that knowledge transfer costs accounted for $2 \%-50 \%$ of the total project cost ranges, so he considered that an important factor in the transfer of knowledge was knowledge transfer costs, and this study also showed that knowledge transfer costs were influenced by three main factors, namely the degree of novelty of the technology transfer, the transfer of experience and the number of 
companies using similar technology, as Table 1.

Wang, Q.X. and Yang, Z. [7] summarized the knowledge transfer following formula: Knowledge transfer $=$ Knowledge convey + Knowledge reception. First, knowledge transfer was issued by the owners of the knowledge transmitted signal to potential recipients, and recipients of selective absorption according to its willingness and ability to accept. And a complete transfer process needed to be communicated and absorption carried out was completed. Hendriks from the communication point of view of knowledge transfer defined, in his view, knowledge transfer was a process of communication and knowledge transfer was among those with knowledge of the recipients. Dixon believed that organizational knowledge transfer referred to the existence of a certain part of the organization's knowledge, in another part of the process within the organization or any other organization with knowledge of organizational members through a variety of tools and procedures for knowledge sharing. These tools include the company database, seminars, e-mail, video conferencing and networking, and so on.

\subsection{Knowledge Transfer Process}

In the study of knowledge transfer process, the Japanese scholar Nonaka's tacit and explicit knowledge from the perspective of the enterprise into each other in four sub-phases of knowledge transfer, proposed "SECI just spiral". The first process of the model is the process of socialization of tacit knowledge that is the process of sharing experiences in order to create a new sense of tacit knowledge, knowledge of this process still exists in the form of tacit knowledge; Second process is the process of converting tacit knowledge to explicit knowledge, which called externalization of knowledge; Third process is a combination of knowledge of the process. This process still only exists in the form of explicit knowledge, in the process of spreading knowledge, fragmentary systematic and explicit knowledge is further complicated; last process is from explicit knowledge to tacit knowledge of the transformation process, known as the process of knowledge, it means outside knowledge begins to become significant personal and exclusive knowledge.

Gibert \& Gordey-Hayes argue that when organizations recognize the lack of certain knowledge within the organization, they have given rise to the knowledge gap, thus creating the behavior of knowledge transfer, knowledge transfer and therefore proposes five-stage mode: Acquisition

1) Communication;

2) Application;

3) Acceptance;

4) Assimilation.

\section{Table 1. Knowledge, knowledge management and knowledge transfer.}

- 4 types: Know-what, Know-why, Know-how, Know-who.

- Tacit knowledge, Explicit knowledge.

- $\quad$ experience of the value of structured information and expert knowledge of the scene mixed.

- result of understanding the world of human society and the crystallization of a powerful tool to create the world's future.

- $\quad$ storage capacity of the human mind to interpret information and conversion information.

- $\quad$ artistic creation from the organization in the value of intangible assets.

- top-down monitoring activities to promote knowledge creation and maintenance knowledge and practical knowledge asset conversion facilities update.

- $\quad$ find a group to get a comprehensive storage management development activities in the dissemination and use of knowledge.

- $\quad$ corporate collective knowledge and skills to help companies capture anywhere in the process to achieve maximum output distribution.

- In certain situations of the propagation from a source of knowledge unit to the receiving unit.

- processes of the organization and the inter-organizational creating interactive spiral.

- reuse organization of individuals or groups in the process of knowledge creation.

- $\quad$ process of transferring knowledge from one department to another department.

- $\quad$ process of transferring knowledge or its techniques applied in different environments, be applied and developed to the better level.

- $\quad$ processes that the received knowledge to be accumulated and lead to the new improved skill.

Source: Chen Limin, Wang Xuan, “2000-2007 Summary of knowledge transfer theory (2009)”. 


\subsection{Knowledge Transfer of Internal Parent Company}

Yu, P. [8] study deepens the understanding of knowledge transfer within the organization; their research reveals the determinants of the flow of knowledge in four areas: 1) Knowledge outward flow to the sibling of subsidiary company; 2) Knowledge outward flow to the parent company; 3) Inflow of knowledge from sibling subsidiaries; 4) Knowledge flows from the parent company into the subsidiary. Gupta \& Govindarajan think flow in-out of the company's knowledge depends on the five factors: 1) The value of the knowledge stored in the source unit; 2) Motivation source units; 3) Transmission channels and richness of existence; 4) Motivational factors of the target unit; 5) Target unit's capacity to absorb. These five factors that can make knowledge transfer more convenient or conversely hinder knowledge transfer.

In particular with regard to the existence of the transmission channel and richness in, Guan, T. [9] pointed out that if the company's internal transmission channel does not exist, then the flow of knowledge multinationals do not exist. The communication channels are divided into formal and informal categories. According to Gupta \& Govindarajan’s research, this study will be divided into formal integration mechanism and social mechanisms.

\section{Research Methodology and Design}

\subsection{Research Model and Basic Assumptions}

According to collating and analyzing the first chapter of the literature review, the researchers are according to the specific circumstances of Taiwan-funded enterprises, the proposed model in this study.

From Figure 1, the factors from the parent-subsidiaries company internal relations proceed, after a summary of the main conclusions of the current cross-strait researchers proposed five dimensions of internal relations, namely the integration of formal relations, social integration mechanisms, the level of trust, organizational distance and cultural. Also, because data is sourced from Taiwan parent company and the China subsidiary company, there are differences between the two main ideas coming from comparison and analysis.

After five dimensions discussed about this, we proposed the following hypothesis as in Table 2.

\subsection{The Design of the Questionnaire}

The questionnaire consists of three parts namely, basic information, relationship between the characteristics of the parent-subsidiary knowledge transfer process, effectiveness of knowledge transfer. Basic Information section is an industry research firm, date of establishment, number of employees, the main work and ownership structure and other aspects.

The second part (Part B) is a research staff in the knowledge transfer process for relationship between the characteristics parent-subsidiary company of cognition.

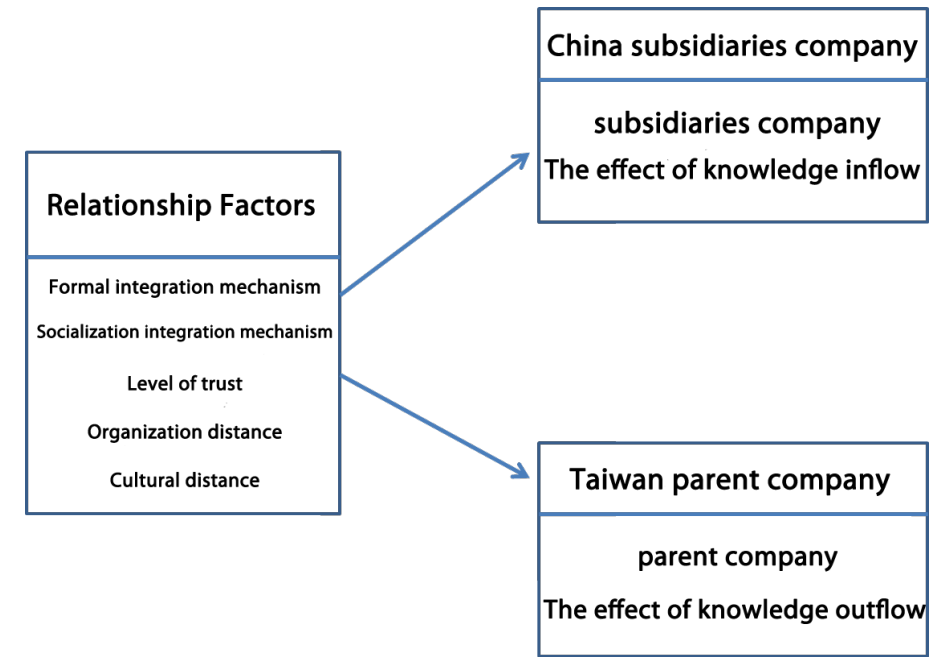

Source: Researchers finishing.

Figure 1. Research model. 
Table 2. Hypothesis.

\begin{tabular}{|c|c|c|c|}
\hline Dimensions & Variable & Assumption & Content \\
\hline \multirow{6}{*}{$\begin{array}{l}\text { Factor of } \\
\text { relationship } \\
\text { between } \\
\text { parent and } \\
\text { subsidiary }\end{array}$} & $\begin{array}{l}\text { Formal } \\
\text { integration } \\
\text { mechanism }\end{array}$ & Assuming 1-2 & $\begin{array}{l}\text { Through formal integration mechanism between the subsidiaries and the parent } \\
\text { company to contact more closely, knowledge will more transfer from the parent } \\
\text { company to the subsidiary company. }\end{array}$ \\
\hline & $\begin{array}{l}\text { Socialization } \\
\text { mechanisms }\end{array}$ & Assuming 2-2 & $\begin{array}{l}\text { Through socialization mechanism between the subsidiaries and the parent company } \\
\text { to contact more closely, knowledge will more transfer from the parent company to } \\
\text { the subsidiary company. }\end{array}$ \\
\hline & & Assuming 3-1 & $\begin{array}{l}\text { The more level of trust of parent company and subsidiary company, knowledge } \\
\text { will more transfer from the parent company to the subsidiary company }\end{array}$ \\
\hline & & Assuming 3-2 & $\begin{array}{l}\text { The more level of trust of parent company and subsidiary company, knowledge } \\
\text { will more transfer from the parent company to the subsidiary company }\end{array}$ \\
\hline & $\begin{array}{l}\text { Organization } \\
\text { distance }\end{array}$ & Assuming 4-2 & $\begin{array}{l}\text { If the distance between the subsidiary and the parent company closer, knowledge } \\
\text { will more transfer from the parent company to the subsidiary company }\end{array}$ \\
\hline & $\begin{array}{l}\text { Cultural } \\
\text { distance }\end{array}$ & Assuming 5-2 & $\begin{array}{l}\text { If between the subsidiary and the parent company culture shorter distance, knowledge } \\
\text { will more transfer from the parent company to the subsidiary company }\end{array}$ \\
\hline
\end{tabular}

Source: Researchers finishing.

1) Knowledge transfer channels;

2) The degree of trust;

3) Organizations distance;

4) Cultural distance.

The third part is the ultimate measure of the effectiveness of knowledge transfer part, this part of the questionnaire on the extent of knowledge transfer using Zhang Yuan and Chen Yi that was proposed to achieve the target transfer case and employee satisfaction scale, while according to Cummings, Kostova's study on access to new knowledge and knowledge makes setting up the questions of performance improvement, the above four points to measure the knowledge of the parent company inflow and outflow effect.

After preparing the questionnaire completed questionnaires in the Nanzih Processing Zone and Mainland Guangdong area, Kaohsiung area was distributed 50 questionnaires, 36 copies, 31 copies of valid questionnaires. In mainland Guangdong Distributed, a total of 54 questionnaires, 48 copies of valid questionnaires. Both the number of questionnaires has reached the required number of samples statistically. Kaohsiung area because of its industrial agglomeration characteristics is mainly the manufacturing industry and the semiconductor industry. Guangdong region questionnaire focused on the high-tech industry.

\section{Data Analysis and Results}

Questionnaire data processing by using SPSS17.0, main analysis methods include reliability and validity analysis, factor analysis, correlation analysis, regression analysis, descriptive statistics. 


\subsection{Descriptive Statistics}

\section{The Companies Involved in the Case Investigation}

As can be seen from both Table 2 and Table 3, the objects of this research are mostly high-tech industry companies, particularly in electronics manufacturing and computer parts, electronics and optics industry, more than the total of five research percent. In terms of ownership structure, the majority of Taiwanese chooses a sole proprietorship form, which is easy to manage and control. In terms of the respondents from the post nuclear pearshaped distribution point presentation, middle managers are the main part of the completed questionnaires.

\subsection{Reliability and Validity Analysis}

The reliability of the questionnaire is to examine the reliability of the questionnaire to measure, and is the degree of internal consistency of the measurement results obtained. Validity of the test from the content validity, face validity and construct validity are the three aspects of starting. Before the questionnaire data analysis, we must examine its reliability and validity, in order to ensure the quality of the measurement.

\section{Reliability Analysis}

In this paper, the consistency Cronbach coefficient ( $\alpha$ coefficient) is to analyze the reliability. Each of the factors is used to test whether each item measured in the same or similar characteristics. Generally believed if $\alpha$ coefficient is high, the reliability of questionnaire will high. Greater than 0.5 are credible range, less than 0.3 should be rejected as in Table 4 .

\subsection{Factor Analysis}

Factor analysis is the study of common factors extracted from the variable group statistical techniques. It is divided into confirmatory factor analysis and exploratory factor analysis. Exploratory factor analysis assumes no prior relationship between the factors and measure items, but the main common factor analysis extracts through the main ingredient. Confirmatory factor analysis assumes that the relationship between factors and entry is part of that measure, that measure items which corresponds to which factor, although even if we do not know the specific factor. In this paper, knowledge transfer performance indicators to measure the dimensions and the initial establishment of the literature is based on previous research, and for a certain model assumptions, we factor

\section{Table 3. Parent (TW) and subsidiary (CH) survey sample distribution table.}

\begin{tabular}{|c|c|c|c|c|c|}
\hline \multirow[b]{2}{*}{ Factor } & \multirow[b]{2}{*}{ Category } & \multicolumn{2}{|c|}{ China } & \multicolumn{2}{|c|}{ Taiwan } \\
\hline & & $\begin{array}{c}\text { Number of } \\
\text { samples }\end{array}$ & $\%$ & $\begin{array}{c}\text { Number of } \\
\text { samples }\end{array}$ & $\%$ \\
\hline \multirow{4}{*}{ Industry } & Electronic parts manufacturing & 14 & $29.2 \%$ & 5 & $16.1 \%$ \\
\hline & Computer, electronic and optical products manufacturing & 1 & $2.1 \%$ & 9 & $29 \%$ \\
\hline & Wholesale and retail trade & 26 & $54.2 \%$ & 2 & $6.5 \%$ \\
\hline & Manufacturing & 7 & $14.6 \%$ & 8 & $25.8 \%$ \\
\hline \multirow{3}{*}{$\begin{array}{l}\text { Ownership } \\
\text { structure }\end{array}$} & Wholly-owned subsidiary of Taiwan-funded & 45 & $93.8 \%$ & 22 & $73.3 \%$ \\
\hline & Joint venture subsidiary, Taiwan-funded holding more than 50\% & 1 & $2.1 \%$ & 6 & $20 \%$ \\
\hline & Joint venture subsidiary, Taiwan-funded holding less than $50 \%$ & 2 & $4.2 \%$ & 2 & $6.7 \%$ \\
\hline \multirow{4}{*}{$\begin{array}{c}\text { Duties } \\
\text { (Subsidiary) }\end{array}$} & High level & 5 & $10.4 \%$ & 3 & $9.7 \%$ \\
\hline & Middle & 38 & $79.2 \%$ & 15 & $48.4 \%$ \\
\hline & Basic level & 4 & $8.3 \%$ & 13 & $41.9 \%$ \\
\hline & Other & 1 & $2.1 \%$ & 0 & 0 \\
\hline
\end{tabular}

Source: Author analysis proceeds by SPSS. 
Table 4. Various indicators of reliability analysis (parent (TW) and subsidiary (CH) Company).

\begin{tabular}{|c|c|c|c|c|c|c|}
\hline \multirow{2}{*}{ Factors } & \multirow{2}{*}{ Formal integration mechanism } & \multirow{2}{*}{ Options } & \multicolumn{2}{|c|}{ China } & \multicolumn{2}{|c|}{ Taiwan } \\
\hline & & & $\alpha$ coefficient & $\alpha$ coefficient & $\alpha$ coefficient & $\alpha$ coefficient \\
\hline \multirow{6}{*}{$\begin{array}{l}\text { Factor of } \\
\text { relationship } \\
\text { between } \\
\text { Parent and } \\
\text { subsidiary }\end{array}$} & Socialization mechanisms & A: $1-5,7$ & 0.576 & \multirow{3}{*}{0.627} & 0.704 & \multirow{3}{*}{0.669} \\
\hline & & & & & & \\
\hline & Level of trust & A: 6,8 & 0.613 & & 0.624 & \\
\hline & Organization distance & B: $1-4$ & 0.569 & & 0.657 & \\
\hline & Cultural distance & B: $5-7$ & 0.573 & 0.624 & 0.623 & 0.716 \\
\hline & Acquire new knowledge & B: $8-10$ & 0.583 & & 0.674 & \\
\hline \multirow{4}{*}{$\begin{array}{l}\text { Assess the } \\
\text { effect of the } \\
\text { inflow and } \\
\text { outflow of } \\
\text { knowledge }\end{array}$} & $\begin{array}{c}\text { The extent of the transfer of knowledge } \\
\text { and satisfaction }\end{array}$ & C: $1-2$ & 0.819 & \multirow{3}{*}{0.805} & 0.722 & \multirow{4}{*}{0.783} \\
\hline & Changes in knowledge resulting from reliance & C: $3-4$ & 0.630 & & 0.517 & \\
\hline & Knowledge makes the performance improvement & C: 5 & - & & - & \\
\hline & Formal integration mechanism & C: $6-7$ & 0.595 & & 0.771 & \\
\hline
\end{tabular}

Source: Author analysis proceeds by SPSS.

analysis to extract the common factors using principal component analysis, one can assume that in contrast with the model, we have become a powerful tool to verify the validity of the model; the other hand, can identify potential factors, to form an effective complement to the model.

Before factor analysis, we must first examine the scale has KMO test sample test and BTS correlation common factor between the various detection methods. KMO sample test is used to index the simple correlation coefficient and partial correlation coefficient between the relatively variable, KMO statistics is a value between 0 and 1 . The KMO value is closer to 1 , the correlation between variables means that the stronger, the more explanatory variables are also suitable for factor analysis; KMO value is closer to 0 , the correlation between variables means that the weaker the more unsuitable original variables factor analysis. According to the requirements, KMO values between 0.6 - 0.8 are suitable for factor analysis. BTS test, Bartlett test sphere, the correlation matrix is not used to test the matrix to reflect the factor model that is not inappropriate.

\subsubsection{Knowledge of Communication}

First of all, we must first look at whether our sample detection is suitable for factor analysis. In the questionnaire, the parent company of the knowledge of the total communication channels KMO and BTS factors were tested. We can see, on the one hand, KMO values of 0.688 and 0.679 , respectively, are above requirements. Therefore it is suitable for factor analysis, on the other hand, Bartlett's tests of sphericity coefficients are significantly less than 0.01, relevant, from another point of view that the data is suitable for factor analysis, as Table 5, Table 6 .

\subsubsection{Parent Company Factor Analysis}

To investigate the relationship between parent and subsidiary is the main factor studied in this article, KMO and Bartlett test results show, KMO parent-subsidiary relationship between 0.702 and 0.635 , respectively, as Table 7, Table 8.

\subsubsection{The Effectiveness of Knowledge Transfer}

It's to verify the effectiveness of knowledge transfer between the mother-child relationship factors that are influential for knowledge transfer evaluation, after analysis, the effectiveness of knowledge transfer KMO 0.693 and 0.635, respectively, as in Table 9 and Table 10.

On the relationship between the parent company and the effectiveness of knowledge transfer factor analysis, statistical results are shown in Table 11. 
Table 5. Knowledge communication channels factor analysis of KMO and Bartlett test (subsidiary).

\begin{tabular}{|c|c|c|}
\hline \multicolumn{3}{|c|}{ KMO and Bartlett’s test } \\
\hline \multicolumn{2}{|c|}{ Sampling sufficient degree of Kaiser-Meyer-Olkin measure } & 0.688 \\
\hline \multirow{3}{*}{ Bartlett's test of sphericity } & Approximate chi-square & 137.918 \\
\hline & df & 15 \\
\hline & Sig. & 0.001 \\
\hline
\end{tabular}

Source: Author analysis proceeds by SPSS.

Table 6. Knowledge communication channels factor analysis of KMO and Bartlett test (parent company).

\section{KMO and Bartlett’s test}

Sampling sufficient degree of Kaiser-Meyer-Olkin measure

Source: Author analysis proceeds by SPSS.

Table 7. KMO and Bartlett test the relationship between the parent companies of factor analysis (subsidiary company).

\begin{tabular}{|c|c|c|}
\hline \multicolumn{3}{|c|}{ KMO and Bartlett's test } \\
\hline \multicolumn{2}{|c|}{ Sampling sufficient degree of Kaiser-Meyer-Olkin measure } & 0.702 \\
\hline \multirow{3}{*}{ Bartlett's test of sphericity } & Approximate chi-square & 348.492 \\
\hline & df & 45 \\
\hline & Sig. & 0.000 \\
\hline
\end{tabular}

Source: Author analysis proceeds by SPSS.

Table 8. KMO and Bartlett test the relationship between the parent companiesof factor analysis (parent company).

KMO and Bartlett's test

Sampling sufficient degree of Kaiser-Meyer-Olkin measure

Approximate chi-square

Bartlett's test of sphericity $\mathrm{df}$

Sig.
0.635

147.279

45

0.000

Source: Author analysis proceeds by SPSS.

Table 9. Factor analysis of the effectiveness of knowledge transfer of KMO and Bartlett test (subsidiary company).

\begin{tabular}{ccc}
\hline KMO and Bartlett's test & \\
\hline Sampling sufficient degree of Kaiser-Meyer-Olkin measure & 0.693 \\
Bartlett's test of sphericity & Approximate chi-square & df \\
\hline
\end{tabular}

Source: Author analysis proceeds by SPSS. 
Table 10. Factor analysis of the effectiveness of knowledge transfer of KMO and Bartlett test (subsidiary company).

\begin{tabular}{|c|c|c|}
\hline \multicolumn{3}{|c|}{ KMO and Bartlett's test } \\
\hline \multicolumn{2}{|c|}{ Sampling sufficient degree of Kaiser-Meyer-Olkin measure } & 0.796 \\
\hline \multirow{3}{*}{ Bartlett's test of sphericity } & Approximate chi-square & 661.974 \\
\hline & $\mathrm{df}$ & 21 \\
\hline & Sig. & 0.000 \\
\hline
\end{tabular}

Source: Author analysis proceeds by SPSS.

Table 11. Factor analysis statistics (Subsidiary company).

\begin{tabular}{|c|c|c|c|c|c|}
\hline Question & Communication channels & $\begin{array}{l}\text { The relationship between parent } \\
\text { and subsidiary companies }\end{array}$ & Effectiveness of knowledge transfer & KMO & BTS \\
\hline A1 & 0.816 & - & - & 0.688 & 0.000 \\
\hline A2 & 0.755 & - & - & - & - \\
\hline A3 & 0.813 & - & - & - & - \\
\hline A4 & 0.753 & - & - & - & 0.000 \\
\hline A5 & 0.798 & - & - & - & - \\
\hline A6 & 0.737 & - & - & - & - \\
\hline A7 & 0.763 & - & - & - & - \\
\hline A8 & 0.849 & - & - & - & - \\
\hline B1 & - & 0.865 & - & 0.702 & 0.000 \\
\hline B2 & - & 0.785 & - & - & - \\
\hline B3 & - & 0.808 & - & - & - \\
\hline B4 & - & 0.841 & - & - & - \\
\hline B5 & - & 0.711 & - & - & - \\
\hline B6 & - & 0.688 & - & - & - \\
\hline B7 & - & 0.766 & - & - & - \\
\hline B8 & - & 0.840 & - & - & - \\
\hline B9 & - & 0.763 & - & - & - \\
\hline B10 & - & 0.852 & - & - & - \\
\hline C1 & - & - & 0.793 & 0.693 & 0.000 \\
\hline C2 & - & - & 0.783 & - & - \\
\hline C3 & - & - & 0.851 & - & - \\
\hline C4 & - & - & 0.651 & - & - \\
\hline C5 & - & - & 0.795 & - & - \\
\hline C6 & - & - & 0.757 & - & - \\
\hline C7 & - & - & 0.739 & - & - \\
\hline
\end{tabular}

Source: Researcher finishing. 
First of all, the vast majority of factors (except a subsidiary B6, parent B3) the consistency reliability $\alpha$ values between $0.7-0.9$, showed good internal consistency factor. Due to questions of organization, B questions of distance measuring have only three, B6 and $\alpha$ values are close to 0.7 , as the research needs to be retained, B3 similarly be retained.

\section{Conclusions}

On the basis of the parent company on multinationals and knowledge transfer, literature review on the Taiwanowned parent company was based on internal knowledge transfer between business relationships and summarized genre theories.

First, the study of knowledge management from the start, in the context of knowledge economy, has become the core competitiveness of enterprises. Knowledge transfer, innovation and imitation will become an inexhaustible motive force to maintain a competitive advantage, and knowledge transfer is the reality of cross-border use for business, due to that internal transaction costs are lower than external transactions and the transfer of knowledge requires cost Penrose, and therefore the presence of multinational companies is in favor of higher pay, from a macro perspective that is also conducive to global economic integration. Secondly [10], due to the current continuous integration and open in the mainland and Taiwan, there has been an increasing number of opportunities, the US-ROK FTA for Taiwan also accelerates the pace of economic restructuring, the mainland excellent infrastructure, highly skilled workforce and extensive market let Taiwan have set up a subsidiary in an attempt to gain new benefits. The current is not much, but due to the limited empirical research conditions, it is difficult to start. Because of the relationship between the author and the research exchange in Taiwan, mainland China and Taiwan can obtain first-hand information for the study of the creation of favorable conditions. After studying contrast, I found the cross-strait cultural similarities, fewer barriers to communication and collaboration which are conducive to the transfer and sharing of knowledge, and the formal integration mechanism compared to more complete integration mechanisms of socialization, a wholly owned subsidiary of the parent company for higher degree of trust, organizational distance, the higher the corporate culture and high-tech companies for the way, which they operate similar requirements.

The innovation of this study is:

1) The relationship among factors of the parent company's impact on the effectiveness of the knowledge transfer benefits from communication channels, the level of trust, organizational and cultural distance from the four levels of analysis, which mainly focused on the characteristics of knowledge, knowledge transfer processes and knowledge transfer scenario compared with previous studies, and it opened up a new direction.

2) Study the contents of Taiwan-funded enterprises due to the condition of the two sides, and few studies involved this area. Researchers in the first half of 2012 had the privilege of doing half of Taiwanese exchange students, and created a favorable opportunity to come into contact with the first-hand information, to facilitate the parent company of Taiwan-funded research.

3) Study questionnaires were distributed to the parent company, comparative studies, and this was an internal transfer of research knowledge multinationals that had not been used before.

4) Studies have found different values for different companies to create subsidiaries "soft power" requirement in which high-tech enterprises pay more attention to corporate culture, and simple manufacturing cost reduction, and focus more on mechanization and process operations.

\section{References}

[1] Kogut, B. and Zander, U. (1992) Knowledge of the Firm, Combinative Capabilities and the Replication Technology. Organization Studies, 3, 383-397.

[2] Kogut, B. and Zander, U. (1993) Knowledge of the Firm and the Evolutionary Theory of the Multinational Corporation. Journal of International Business Studies, 24, 625-646. http://dx.doi.org/10.1057/palgrave.jibs.8490248

[3] Gupta, A.K. and Govindarajan, V. (2000) Knowledge Flows within Multinational Corporations. Strategic Management Journal, 21, 473-496. http://dx.doi.org/10.1002/(SICI)1097-0266(200004)21:4<473::AID-SMJ84>3.0.CO;2-I

[4] Chini, T.C. (2004) Effective Knowledge Transfer in Multinational Corporation. Palgrave Macmillan, New York. http://dx.doi.org/10.1057/9780230005877

[5] Drucker, P. (1999) Knowledge Management. Renmin University of China Press, Beijing. 
[6] Xu, J.F. and Liu, Y. (2002) Determine the Flow of Knowledge between the Multinational Factors. Journal of Science Research management, 2, 122-126.

[7] Wang, Q.X. and Yang, Z. (2005) Multinational Parent Company Knowledge Transfer between Research: A Contextual Perspective. Science of Science and Management, 6, 61-86.

[8] Yu, P. (2006) Multinational Internal Knowledge Transfer Research. Ph.D. Thesis, Shandong University, Jinan, 117.

[9] Guan, T. (2005) Empirical Research Multinational Internal Knowledge Transfer Process and Influencing Factors. Ph.D. Thesis, Fudan University, Shanghai, 25.

[10] Li, Y.N. (2009) The Parent Company Transfer Research Knowledge. Ph.D. Thesis, Shandong University, Jinan, 16. 